\title{
Peroxisome Proliferator Activator Receptor Gamma Coactivator-1 $\alpha$ Overexpression in Amyotrophic Lateral Sclerosis: A Tale of Two Transgenics
}

\author{
Merina Varghese ${ }^{1,+}\left(\mathbb{D}\right.$, Wei Zhao ${ }^{1,+}$, Kyle J. Trageser ${ }^{1}(\mathbb{D})$ and Giulio M. Pasinetti ${ }^{1,2, *(D)}$ \\ 1 Department of Neurology, Icahn School of Medicine at Mount Sinai, New York, NY 10029, USA; \\ merina.varghese@mssm.edu (M.V.); wei.zhao@mssm.edu (W.Z.); kyle.trageser@mssm.edu (K.J.T.) \\ 2 Geriatric Research, Education and Clinical Center, James J. Peters Veterans Affairs Medical Center, Bronx, \\ New York, NY 10468, USA \\ * Correspondence: giulio.pasinetti@mssm.edu; Tel.: +1-(212)-241-7938; Fax: +1-(212)-876-9042 \\ $\dagger$ These authors contributed equally to the study.
}

Received: 20 April 2020; Accepted: 11 May 2020; Published: 13 May 2020

\begin{abstract}
Amyotrophic lateral sclerosis (ALS) is a progressive neurodegenerative disorder manifesting with upper and lower neuron loss, leading to impairments in voluntary muscle function and atrophy. Mitochondrial dysfunction in metabolism and morphology have been implicated in the pathogenesis of ALS, including atypical oxidative metabolism, reduced mitochondrial respiration in muscle, and protein aggregates in the mitochondrial outer membrane. Peroxisome proliferator-activated receptor $\gamma$ coactivator- $1 \alpha$ (PGC- $1 \alpha$ ) plays an essential role in the regulation of mitochondrial biogenesis, the process by which existing mitochondria grow and divide. PGC- $1 \alpha$ has been previously reported to be downregulated in the spinal cord of individuals with ALS. Towards targeting PGC-1 $\alpha$ as a therapeutic mechanism, we have previously reported improved motor function and survival in the SOD1 $1^{\mathrm{G} 93 \mathrm{~A}}$ mouse model of ALS by neuron-specific over-expression of PGC-1 $\alpha$ under a neuron-specific enolase (NSE) promoter. As pharmacological intervention targeting PGC- $1 \alpha$ would result in whole-body upregulation of this transcriptional co-activator, in the current study we investigated whether global expression of PGC- $1 \alpha$ is beneficial in a SOD1 ${ }^{\mathrm{G} 93 \mathrm{~A}}$ mouse model, by generating transgenic mice with PGC- $1 \alpha$ transgene expression driven by an actin promoter. Actin-PGC- $1 \alpha$ expression levels were assayed and confirmed in spinal cord, brain, muscle, liver, kidney, and spleen. To determine the therapeutic effects of global expression of PGC- $1 \alpha$, wild-type, actin-PGC-1 $\alpha$, SOD1 ${ }^{\mathrm{G} 93 \mathrm{~A}}$, and actin-PGC- $1 \alpha / \mathrm{SOD} 1 \mathrm{G} 93 \mathrm{~A}$ animals were monitored for weight loss, motor performance by accelerating rotarod test, and survival. Overexpression of actin-PGC-1 $\alpha$ did not confer significant improvement in these assessed outcomes. A potential explanation for this difference is that the actin promoter may not induce levels of PGC- $1 \alpha$ relevant to disease pathophysiology in the cells that are specifically relevant to the pathogenesis of ALS. This evidence strongly supports future therapeutic approaches that target PGC- $1 \alpha$ primarily in neurons.
\end{abstract}

Keywords: mitochondrial biogenesis; motor function; neurodegeneration; tissue-specific expression

\section{Introduction}

Amyotrophic lateral sclerosis (ALS), also known as Lou Gehrig's disease, is a neurological disorder affecting motor neurons and leading to progressive loss of voluntary muscle function, paralysis, and ultimately death. ALS can be either inherited or sporadic; whereas $10 \%$ of cases are familial ALS (fALS) with inherited mutations in genes including TDP-43, FUS, C9ORF72, and SOD1, 90\% are classified as sporadic ALS (sALS), for the majority of which the cause is unknown [1]. 
The etiopathogenesis of ALS is incompletely understood. However, it is believed that ALS is a multifactorial disease with deficits in various facets of the normative function of the cell, including oxidative stress and aberrant mitochondrial function [2]. Mitochondrial bioenergetics are increased in the neocortex of patients with fALS as compared to controls [3,4]. In human $\mathrm{Cu} / \mathrm{Zn}$ superoxide dismutase 1 (SOD1) mouse models of ALS, ALS-associated variants of SOD1 protein were abnormally imported into spinal cord mitochondria $[5,6]$. The SOD1 ${ }^{\mathrm{G} 93 \mathrm{~A}}$ mutant, a commonly studied model of fALS, causes decreased mitochondrial respiration [6,7] and increased fragmentation of the organelle [8] compared to wild-type controls, leading to loss of neurons in the anterior horn of the spinal cord [9]. In vitro studies implicate similar mitochondrial functional and structural changes in fibroblasts expressing mutant TDP-43 and C9ORF72 [10]. Mitochondrial functional changes have also been reported in sALS, including reduced mitochondrial respiration in skeletal muscle [11] and fibroblasts [12], increased bioenergetic function in fibroblasts [13], but no alteration in mitochondrial respiration in the spinal cord [4]. Reports of changes in the complexity of the mitochondrial network vary, with either loss of age-related complexity [12] or no changes [14] reported. Mitochondrial abnormalities may represent a disease mechanism shared by both sALS and fALS [15].

The altered mitochondrial structure and function observed in ALS may result from the dysfunction of various mechanisms, which under normal conditions act to maintain proper homeostasis of the organelle. Affected homeostatic mechanisms in ALS include altered axonal transport, fission/fusion, mitophagy, and biogenesis of mitochondria. Mitochondrial biogenesis, the process by which mitochondria grow and replicate, is regulated by the transcription co-activator peroxisome proliferator-activated receptor gamma, coactivator 1 alpha (PPARGC1A or PGC-1 $\alpha$ ) [16]. Underscoring the relevancy of PGC- $1 \alpha$ to the pathogenesis of ALS, PGC- $1 \alpha$ expression has been shown to be reduced in the muscles $[17,18]$, motor cortex, and spinal cord motor neurons of ALS patients ${ }^{17}$, as well as in muscle $[17,19]$ and spinal cord of the SOD1 ${ }^{\mathrm{G} 93 \mathrm{~A}}$ mouse model of ALS [17].

We hypothesized that increasing mitochondrial mass through PGC- $1 \alpha$ over-expression may lead to protection in ALS neurodegeneration. A previous study from our group found improved motor function and survival following neuronal overexpression of PGC- $1 \alpha$ in the SOD1 ${ }^{\mathrm{G} 93 \mathrm{~A}}$ mouse model of ALS, driven by the neuron-specific enolase (NSE) promoter [20]. Therapeutic interventions often have pleiotropic, off-target effects on unintended cell types, and delivery to a specific cell type may not directly translate to clinical practice. Therefore, we investigated if beneficial effects could be achieved in the same mouse model used for our previous studies if PGC- $1 \alpha$ is increased throughout the body. To better understand the effects of PGC- $1 \alpha$ over-expression in the whole body, we tested the effects of the transgene expressed by the ubiquitous beta-actin promoter, which is active in most cells, including neurons, in the SOD1 ${ }^{\mathrm{G} 93 \mathrm{~A}}$ mice on body weight, motor function, and survival.

\section{Materials and Methods}

\subsection{Generation of Actin-PGC-1 $\alpha$ Mice and Crossing with SOD $1^{\text {G93A }}$ Mice}

For global PGC- $1 \alpha$ transgene expression driven by the actin promoter, the plasmid vector pCAGGS ${ }^{20}$ containing the cytomegalovirus immediate-early (CMV-IE) enhancer and chicken $\beta$-actin promoter was modified by inserting a NotI site at the vector XbaI site and a SalI site at the vector HindIII site. Then, the 3.1 kb human PGC-1 $\alpha$ (hPGC-1 $\alpha$ ) cDNA (NM_013261.2; obtained from OriGene Technologies, Inc., Rockville, MD, USA) was inserted in the NotI site (Figure 1), followed by SalI digestion to release a $\sim 6 \mathrm{~kb}$ fragment containing the CMV-IE enhancer, chicken $\beta$-actin promoter, and hPGC- $1 \alpha$. The fragment was gel purified and microinjected into one-cell mouse eggs as described previously [20]. Actin-PGC-1 $\alpha$ founders were identified by PCR-based genotyping using the primers in Table 1 . The generation of NSE-PGC-1 $\alpha$ mice is described in our earlier study [20]. All restriction enzymes were purchased from New England BioLabs (Ipswich, MA, USA). 


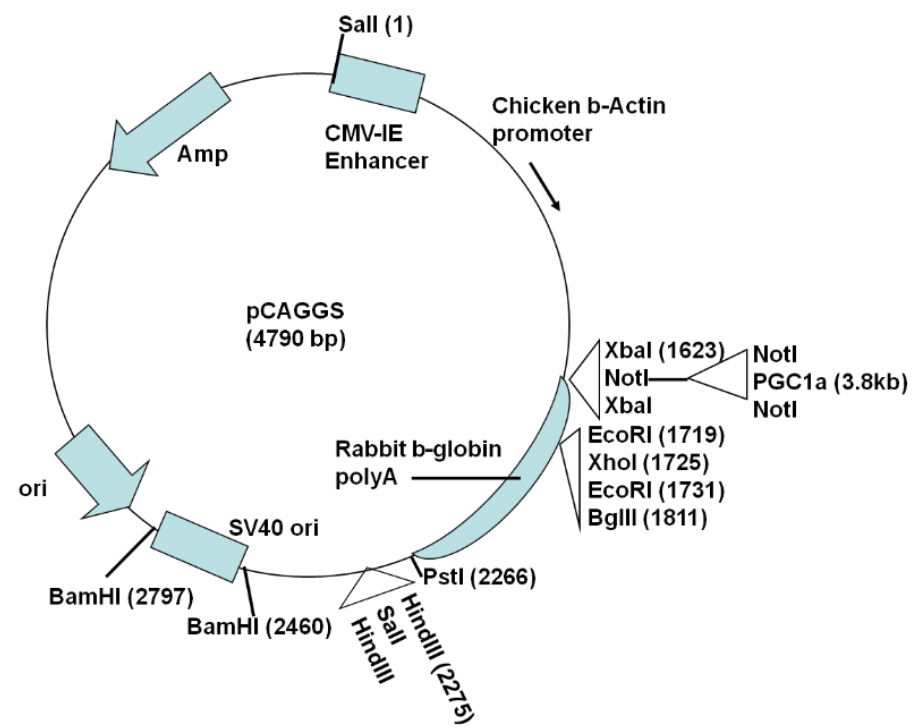

Figure 1. Plasmid construct for generation of actin-PGC- $1 \alpha$ transgenic mice. A NotI site was inserted at the vector XbaI site and a SalI site inserted at the vector HindIII site on the pCAGGS plasmid. Human peroxisome proliferator-activated receptor gamma, coactivator 1 alpha (PGC- $1 \alpha$ ) cDNA was inserted in the NotI site and SalI digestion released the fragment containing the cytomegalovirus immediate-early (CMV-IE) enhancer, chicken $\beta$-actin promoter, and hPGC- $1 \alpha$ that was used for microinjection.

Table 1. PCR primers used in the study.

\begin{tabular}{ccc}
\hline Gene & Primer Orientation & Sequence $\left(\mathbf{5}^{\prime}-\mathbf{3}^{\prime} \mathbf{)}\right.$ \\
\hline & \multicolumn{2}{c}{ Genotyping Primers } \\
pCAGGS & Forward & GGTTCGGCTTCTGGCGTG \\
Human PGC-1 $\alpha$ & Reverse & CCACAGGGAGACTGTCTAGTGTC \\
Mouse IL-2 & Forward & CTAGGCCACAGAATTGAAAGATCT \\
& Reverse & GTAGGTGGAAATTCTAGCATCATCC \\
Human PGC-1 $\alpha$ & Forward & CAGCR Primers \\
& Reverse & TCCTCGTAGCTGTCATACCTG \\
Mouse PGC-1 $\alpha$ & Forward & AAGGTCCCCAGGCAGTAGAT \\
& Reverse & CATAGCTGTCGTACCTGGGC \\
Mouse tubulin & Forward & TAGCAGAGATCACCAATGCC \\
& Reverse & GGCAGCAAGCCATGTATTTA \\
\hline
\end{tabular}

Male TgSOD1 ${ }^{\mathrm{G} 93 \mathrm{~A}}$ mice (C57BL6 $\times$ SJL background) were purchased from the Jackson Laboratory (Bar Harbor, ME, USA) and bred with female actin-PGC- $1 \alpha$ transgenic mice. The resulting litters consisted of double transgenic TgSOD ${ }^{\mathrm{G} 93 \mathrm{~A}} / \mathrm{Tg}$ Actin-PGC- $1 \alpha$ mice, single transgenic TgSOD $1{ }^{\mathrm{G} 93 \mathrm{~A}}$ and TgActin-PGC-1 $\alpha$ mice, as well as wild-type (WT) mice. In our previous study [20], protection with PGC-1 $\alpha$ over-expression was only observed in female mice (data not shown), hence we focused on female mice in this study. The mice were maintained in the transgenic mouse facility on a 12-h light-dark cycle, with free access to food and water. All animal protocols used in the study were approved by the Institutional Animal Care and Use Committee of the Icahn School of Medicine at Mount Sinai.

\subsection{Analysis of Tissue Expression of Exogenous and Endogenous PGC-1 $\alpha$ and Sirtuins}

Four WT, NSE-PGC- $1 \alpha$, and actin-PGC- $1 \alpha$ mice (two of each sex) were sacrificed by carbon dioxide inhalation. The spinal cord, brain, muscle, liver, kidney, and spleen were dissected out, frozen, and stored at $-80^{\circ} \mathrm{C}$. The tissues were homogenized using a Precellys 24 (Bertin Technologies, Montigny-le-Bretonneux, France), with beads to facilitate disruption of the muscle tissue. Muscle RNA 
was isolated using TRIzol reagent (Invitrogen, Carlsbad, CA, USA) as per the recommended protocol from the manufacturer. RNA was isolated from the other tissues using the RNAeasy mini kit (Qiagen, Germantown, MD, USA) as per the manufacturer's instructions and cDNA was prepared from the isolated RNAs using the Superscript III First Strand Synthesis System (Invitrogen). The hPGC-1 $\alpha$ and mouse PGC-1 $\alpha$ genes were amplified using DreamTaq master mix (Thermo Scientific, Waltham, MA, USA), with mouse tubulin as the housekeeping control, using the primers indicated in Table 1.

\subsection{Assessment of Motor Performance, Body Weight, and Survival}

The animals were monitored once a week for general health. Body weight was recorded starting at 9 weeks of age. Motor performance was assessed using an accelerated rotarod (7650 Ugo Basile Biological Research Apparatus, Comerio, Italy) as described earlier ${ }^{18}$. Briefly, the mice were placed on the rotarod, set to accelerate from 2 to 40 rotations per minute over a $5 \mathrm{~min}$ period. The times at which the mice could no longer hold onto the rotarod were recorded as latency to fall. Mice were acclimatized to the experimenter and the apparatus for a week prior to initiation of testing. Each mouse was tested three times per day, and the mice were tested once a week starting at age 9 weeks for the duration of the study. To keep external stimuli constant, the test was conducted in the last $4 \mathrm{~h}$ of the light cycle, in a room with minimal disturbances of sound, movement, light, and temperature. The end point for the survival study was determined as meeting any of the following criteria: no spontaneous breathing or movement for $1 \mathrm{~min}$ with no response to pain, inability to correct position in $10 \mathrm{~s}$ when pushed over, or total hind limb paralysis.

\subsection{Statistics}

Statistical analyses were performed using SigmaStat (version 3.0, SPSS Inc., Chicago, IL, USA). Independent measures $t$-tests were used to compare endpoints. Deterioration of motor function (rotarod testing) was assessed by the Kaplan-Meier survival analysis (Mantel-Cox log rank test) with "failure" defined as the inability of an animal to achieve at least $50 \%$ of its baseline motor performance. This endpoint was chosen because it is a measure that is distinctly related to entry criteria, is the midline of an inexorable decline in strength, and is not influenced by observer bias and animal adaptive skills used when the animal is very weak (e.g., holding on to the rotating rod without walking). A nonparametric time to failure analysis was chosen since a two-way repeated measures ANOVA could not be performed because the data failed both normality and equal-variance tests. Animals' body weight data were analyzed by a two-way repeated measures ANOVA with Huynh-Feldt correction. ANOVA tests were followed, when significant, by the Student-Newman-Keuls multiple comparison tests. The Student-Newman-Keuls test was chosen for post hoc multiple comparisons due to its generally higher sensitivity compared to the Bonferroni test. In all tests, results with probability values less than 0.05 were considered statistically significant. Presented data are shown as mean \pm SEM.

\section{Results}

\subsection{Assessment of Tissue Transgene Expression in NSE-PGC-1 $\alpha$ and Actin-PGC-1 $\alpha$ Mice}

To assess the tissue-specificity of human PGC-1 $\alpha$ expression under the NSE and actin promoters, we extracted RNA from various tissues and performed PCRs with primers specific to hPGC- $1 \alpha$, mouse PGC-1 $\alpha$, and mouse tubulin. Transgene expression was tested in spinal cord, brain, muscle, liver, kidney, and spleen. As would be expected for a transgene expressed under the actin promoter, in the actin-PGC- $1 \alpha$ mice, the transgene was expressed in all the tissues tested (Figure 2). Whereas PGC- $1 \alpha$ expression was present as expected in the spinal cord and brain of the NSE-PGC-1 $\alpha$ mice and absent in the kidney and liver, there was also some expression of the transgene in the muscle and spleen (Figure 2). 


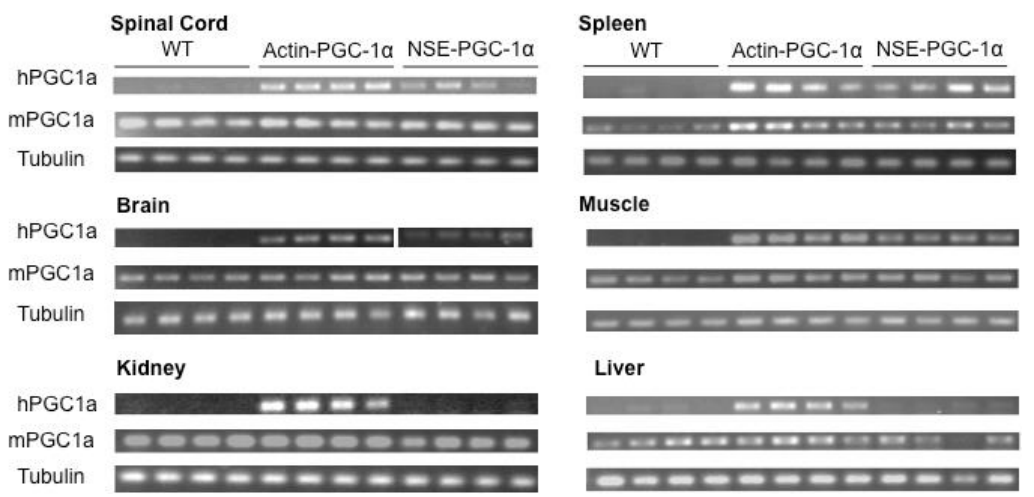

Figure 2. Tissue specificity of PGC- $1 \alpha$ transgene expression. RNA was isolated from the brain, spinal cord, muscle, liver, kidney, and spleen of wild-type (WT), actin-PGC- $1 \alpha$, and NSE-PGC- $1 \alpha$ mice. Expression of human PGC- $1 \alpha$, mouse PGC- $1 \alpha$, and mouse tubulin were detected following RT-PCR. Data are from $n=4$ mice per group.

\subsection{Motor Performance, Survival, and Body Weight Were Not Affected by Actin-PGC-1 $\alpha$ Overexpression}

Whole-body expression of hPGC-1 $\alpha$ under the actin promoter did not result in significant changes in rotarod performance (Figure 3A) or body weight (Figure 3C) as compared to WT mice. Global expression of the PGC- $1 \alpha$ transgene in SOD $1^{\mathrm{G} 93 \mathrm{~A}}$ mice did not improve the decline in motor function that set in by 14 weeks of age (Figure 3A); in fact, the double-transgenic mice performed worse than WT mice even at the pre-symptomatic stage. There was no improvement in the survival of the SOD1 ${ }^{\mathrm{G} 93 \mathrm{~A}}$ transgenic following expression of the PGC- $1 \alpha$ transgene (Figure 3B). The SOD1 ${ }^{\mathrm{G} 93 \mathrm{~A}} /$ actin-PGC- $1 \alpha$ double transgenic mice lost weight at a rate similar to the $\mathrm{SOD} 1^{\mathrm{G} 93 \mathrm{~A}}$ transgenic starting at the 17th week of age (Figure 3C,D).
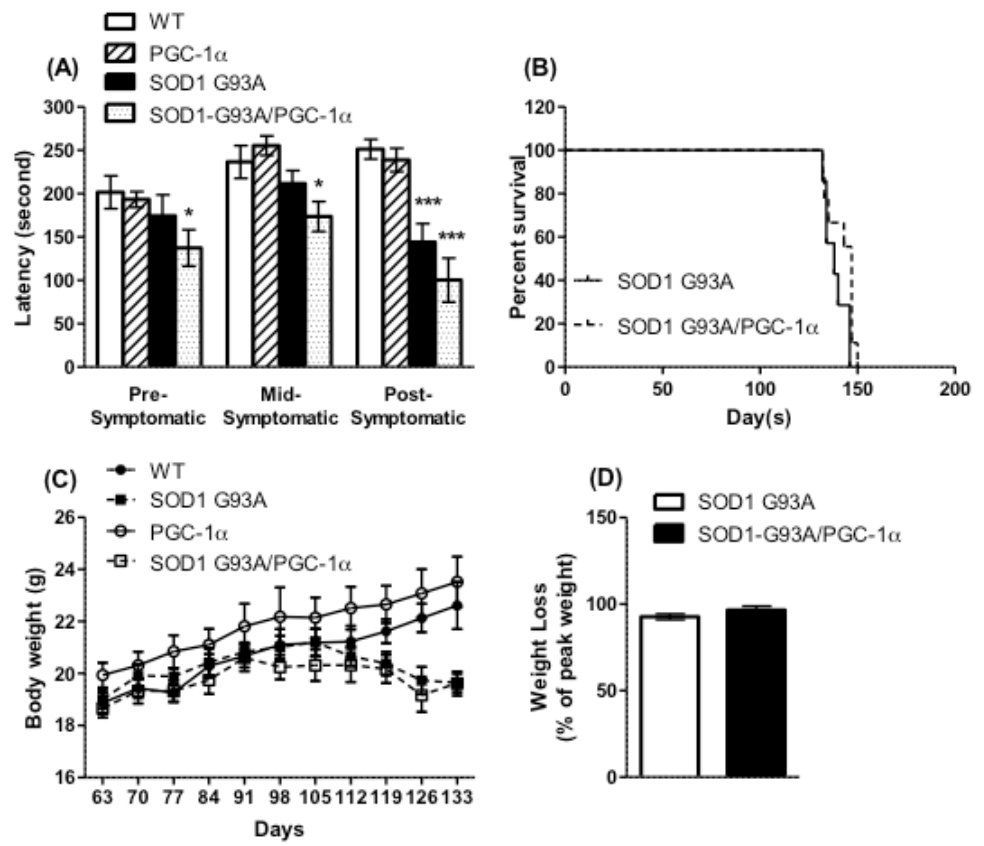

Figure 3. Motor function, survival, and body weight were not improved by actin-PGC-1 $\alpha$ expression. (A) Motor function was assessed by the accelerating rotarod test. The double-transgenic

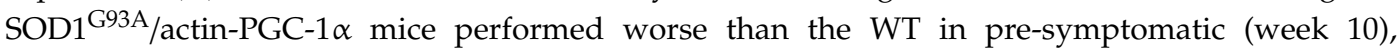
mid-symptomatic (week 14), and post-symptomatic (week 17) stages. Data are mean \pm SEM from $n=10$ WT and 11 SOD $1{ }^{\mathrm{G} 93 \mathrm{~A}}$ mice. ${ }^{*} p \leq 0.05,{ }^{* * *} p \leq 0.001$ as compared to WT by two-tailed Students' $t$-test. (B) Survival was not changed in the SOD1 ${ }^{\mathrm{G} 93 \mathrm{~A}}$ mice by expression of actin-PGC-1 $\alpha$. (C,D) The loss of body weight seen in SOD1 ${ }^{\mathrm{G} 93 \mathrm{~A}}$ mice was not significantly altered by the expression of actin-PGC-1 $\alpha$. 


\section{Discussion}

Our previous studies supported the beneficial effects of PGC- $1 \alpha$ expression in neurons, while the present study failed to establish beneficial effects of exogenous actin promoter-driven PGC- $1 \alpha$ expression in multiple cells, including neurons. These results are puzzling given that actin is ubiquitously expressed. Further, we had anticipated both increased mitochondrial antioxidant capacity and suppressed inflammation, as has been observed in astrocytes [21]. Observations in line with these prior results seem to be contradictory. These results suggest that future studies involving the development of PGC-1 $\alpha$-targeting therapeutics focus on cell-specific lines of investigation.

The choice of ALS model could explain the differences in the protective effects of global PGC- $1 \alpha$ expression. We found that neuron-specific, but not global, over-expression of PGC- $1 \alpha$ was protective in the SOD1 ${ }^{\mathrm{G} 93 \mathrm{~A}}$ mouse model of ALS. Other groups found that whole-body expression of PGC- $1 \alpha$ improved motor function and survival in SOD1G93A DL mice [19], and muscle-specific PGC- $1 \alpha$ expression in LoxSOD1 ${ }^{\mathrm{G} 37 \mathrm{R}}$ mice improved motor function, but not survival [22]. The SOD1 ${ }^{\mathrm{G} 93 \mathrm{~A} D \mathrm{DL}}$ model has about 10 copies of the mutant SOD1 gene and a longer life span (39-42 weeks) than the SOD1 ${ }^{\mathrm{G} 93 \mathrm{~A}} 1 \mathrm{Gur} / \mathrm{J}$ mice (19-23 weeks) used in our study, which have higher copy numbers of the mutant SOD1 gene (18 copies) and exhibit accelerated onset of the ALS phenotype (14-16th week onset compared to 34th week onset in the SOD1 G93A DL model) [23,24]. Meanwhile, the disease end stage for LoxSOD1 ${ }^{\text {G37R }}$ mice with the highest mutation load was between 37 and 48 weeks [25].

We showed previously, in the same ALS mouse model as was used this study, that PGC-1 $\alpha$ targeted ectopic expression under the NSE promoter significantly improves motor function and survival [20]. In the current study, systemic ectopic expression of PGC1a did not significantly improve the body weight, motor function, or survival. In our current study, we tested expression levels of PGC- $1 \alpha$ in tissue homogenates. However, as tissue homogenates consist of multiple types of cells, drawing conclusions regarding the expression of PGC- $1 \alpha$ in a single cell type was not feasible with our methodology. The absence of protective effects of the overexpression of PGC- $1 \alpha$ may be a consequence of inadequate expression in cell types integral to the pathogenesis of ALS, such as motor neurons. In the current study, PGC- $1 \alpha$ expression was higher for the actin promoter than for the NSE promoter in the homogenates of all tissues tested. It is however possible that the level of actin-PGC- $1 \alpha$ in motor neurons is lower than levels of PGC- $1 \alpha$ when expressed under the NSE promoter, and the actin promoter may be insufficient to induce significant beneficial effects. The reason for this discrepancy remains unknown.

PGC- $1 \alpha$ expression is dynamic; in order to meet the tissue's energy demands, PGC- $1 \alpha$ is upregulated or downregulated through multiple mechanisms [26]. However, as our global expression of PGC- $1 \alpha$ was coupled to the constitutively actively expressed $\beta$-actin promoter, there may be compensatory mechanisms occurring, by which the animal quickly adapted. Future investigations to address this possibility may better inform the discrepancy noted in symptom improvement between the global expression of PGC- $1 \alpha$ under the $\beta$-actin promoter versus ectopic expression under the NSE promoter.

Limited information from previous studies is available regarding the relative strength of the actin versus NSE promoter in cells that are potentially relevant to the pathogenesis of ALS. For instance, in the spiral ganglion cells of mouse cochlea, EGFP levels induced by AAV transduction under the actin and the NSE promoters are similar [27]. GFP expression produced by transduction with AAV leads to approximately 3-fold higher expression under the actin versus the NSE promoter in the rat hippocampus [28]. The pertinence of this information to our study remains unclear, as these data refer to tissue homogenates rather than to neurons.

Our current study underscores the importance of characterizing the effects of a pharmacologic intervention on the specific cell type of interest that most contributes to disease pathology-in this case, motor neurons. Further studies will be dedicated to the comparative analysis of PGC- $1 \alpha$ expression driven by actin versus NSE promoters across various cell types. Cell-specific analysis may better elucidate the relative contributions of different cell types to ALS pathology (e.g., neurons versus glia). 
Additionally, cell-specific analysis may indicate which cells are most relevant for predicting the effects of pharmacological agents and for monitoring the expected efficacy.

Interestingly, PGC-1 $\alpha$ appears to have a gender-specific effect in SOD1 ${ }^{\mathrm{G} 93 \mathrm{~A}}$ mice; absence of the PGC-1 $\alpha$ gene leads to earlier onset of the ALS phenotype only in males [29]. Female mice have previously been demonstrated to have a higher level of PGC- $1 \alpha$, which is subsequently reduced when ovariectomized [30]. In an additional study in ovariectomized rats, when they were treated with $17 \beta$-estradiol, PGC- $1 \alpha$ increased in skeletal muscle [31]. We also observed a difference in protection in SOD1 ${ }^{\mathrm{G} 93 \mathrm{~A}}$ mice when over-expressing PGC-1 $\alpha$ in neurons [20]; however, in our study, it was female mice that were protected by the higher levels of PGC-1 $\alpha$ (data not shown). Sex hormone interaction may be driving the different responses to PGC- $1 \alpha$ modulation.

The lack of protective effects in ALS mice when PGC- $1 \alpha$ was globally expressed, as opposed to specifically in neurons, points to potential effects of PGC- $1 \alpha$ expression on non-neuronal cell types such as glia. PGC- $1 \alpha$ has been shown to regulate the transcription of myelin basic protein and cholesterol synthesis enzymes, thereby affecting myelination in the brain [32]. Pioglitazone, an anti-diabetic drug and agonist of peroxisome proliferator-activated receptor- $\gamma$ (PPAR $\gamma)$, improved motor function and survival in SOD1 ${ }^{\mathrm{G} 93 \mathrm{~A}}$ mice by protecting neurons and reducing the activation of microglia and astrocytes in spinal cord $[33,34]$. Another study indicated that neuronal protection by pioglitazone was mediated through neuronal p38 mitogen-activated protein kinase and reduced glial activation via nuclear factor- $\mathrm{KB}$, potentially independent of PPAR- $\gamma$ [35]. Our previous study showed that neuron-specific expression of PGC- $1 \alpha$ was capable of reducing the activation of p38 mitogen-activated protein kinase [20], indicating a mechanism of action similar to pioglitazone in neuronal protection. However, it is not clear whether the interaction of PGC- $1 \alpha$ with PPAR- $\gamma$ would have a similar action on glial proliferation to pioglitazone. Of note, a clinical trial with pioglitazone did not show additional improvement in patients with ALS who were on riluzole treatment [36]. This further underlines the importance of understanding the pathways by which PGC- $1 \alpha$ exerts its effects on neuronal and whole-body function in ALS, and of validating the beneficial effects of modulating neuron-specific expression of the co-activator using other models of ALS.

\section{Conclusions}

Our study demonstrated that while the over-expression of PGC- $1 \alpha$ in neurons in an ALS mouse model has protective effects, overexpression throughout the body driven by the actin promoter does not confer protective effects. Further investigations are underway to determine the exact mechanisms for the difference in phenotypic response to differential expression of PGC- $1 \alpha$. These investigations will continue to compare PGC- $1 \alpha$ expression, induced by multiple promoters, and will possibly target independent cell types in the brain and periphery. Further, the main information provided by the study is that the expression of PGC- $1 \alpha$ throughout the body is insufficient to induce beneficial effects. The study suggests that it is essential to achieve a level of PGC- $1 \alpha$ above a certain threshold in order to confer protective effects. This study suggests for the first time that PGC- $1 \alpha$ expression in cell types other than neurons, thought to be important for the ALS pathology (e.g., glial cells), cannot substitute for robust neuronal expression. This evidence has profound implications for future investigations exploring novel therapeutics in ALS targeting, for example, multiple mechanisms in independent cell types in the brain.

Author Contributions: M.V. wrote the paper, and designed and supervised the gene expression experiments for the NSE-PGC- $1 \alpha$ and actin-PGC- $1 \alpha$ mice. W.Z. designed the study for SOD1 ${ }^{\text {993A }}$ mice crossed with actin-PGC-1 $\alpha$, supervised the animal experiments, and analyzed the data. G.M.P. provided the laboratory resources and overall supervision of the study. K.J.T. wrote and revised the paper and analyzed data. All authors have approved the final article. All authors have read and agreed to the published version of the manuscript.

Funding: This study was supported by discretionary funding to G.M.P. by the NCCIH/ODS (P50 AT008661). G.M.P. also holds a Senior VA Career Scientist Award (IK6 BX003785). We acknowledge that the contents of this study do not represent the views of the NCCIH, the ODS, the NIH, the U.S. Department of Veterans Affairs, or the United States Government. 
Acknowledgments: The actin-PGC- $1 \alpha$ and NSE-PGC- $1 \alpha$ transgenic mice were generated at the Mouse Genomics Shared Resource Facility at the Icahn School of Medicine at Mount Sinai. Real-time PCR experiments were performed at the Quantitative PCR Shared Resource Facility at Mount Sinai. The authors are grateful to Aurelian Radu and Sherry Simkovic for assistance with editing the manuscript and thank Jun Wang for the technical support.

Conflicts of Interest: No conflicts of interest exist for any of the authors.

\section{Abbreviations}

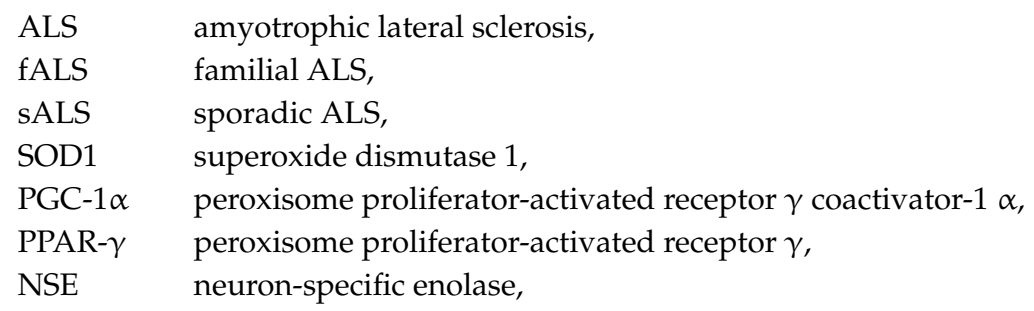

\section{References}

1. Renton, A.E.; Chiò, A.; Traynor, B.J. State of play in amyotrophic lateral sclerosis genetics. Nat. Neurosci. 2014, 17, 17-23. [CrossRef]

2. Shi, P.; Gal, J.; Kwinter, D.M.; Liu, X.; Zhu, H. Mitochondrial dysfunction in amyotrophic lateral sclerosis. Biochimica et Biophysica Acta-Mol. Basis Dis. 2010, 1802, 45-51. [CrossRef]

3. Bowling, A.C.; Schulz, J.B.; Brown, R.H.; Beal, M.F. Superoxide Dismutase Activity, Oxidative Damage, and Mitochondrial Energy Metabolism in Familial and Sporadic Amyotrophic Lateral Sclerosis. J. Neurochem. 1993, 61, 2322-2325. [CrossRef]

4. Browne, S.E.; Bowling, A.C.; Baik, M.J.; Gurney, M.; Brown, R.H., Jr.; Beal, M.F. Metabolic Dysfunction in Familial, but Not Sporadic, Amyotrophic Lateral Sclerosis. J. Neurochem. 2002, 71, 281-287. [CrossRef] [PubMed]

5. Liu, J.; Lillo, C.; Jonsson, P.A.; Velde, C.V.; Ward, C.M.; Miller, T.M.; Subramaniam, J.R.; Rothstein, J.D.; Marklund, S.; Andersen, P.M.; et al. Toxicity of familial ALS-linked SOD1 mutants from selective recruitment to spinal mitochondria. Neuron 2004, 43, 5-17. [CrossRef] [PubMed]

6. Mattiazzi, M.; D’Aurelio, M.; Gajewski, C.D.; Martushova, K.; Kiaei, M.; Beal, M.F.; Manfredi, G. Mutated human SOD1 causes dysfunction of oxidative phosphorylation in mitochondria of transgenic mice. J. Biol. Chem. 2002, 277, 29626-29633. [CrossRef]

7. Kirkinezos, I.G.; Bacman, S.R.; Hernandez, D.; Oca-Cossio, J.; Arias, L.J.; Perez-Pinzon, M.A.; Bradley, W.G.; Moraes, C.T. Cytochrome $\mathrm{c}$ association with the inner mitochondrial membrane is impaired in the CNS of G93A-SOD1 mice. J. Neurosci. 2005, 25, 164-172. [CrossRef] [PubMed]

8. Song, W.; Song, Y.; Kincaid, B.; Bossy, B.; Bossy-Wetzel, E. Mutant SOD1G93A triggers mitochondrial fragmentation in spinal cord motor neurons: Neuroprotection by SIRT3 and PGC-1 $\alpha$. Neurobiol. Dis. 2013, 51, 72-81. [CrossRef]

9. Dal Canto, M.C.; Gurney, M.E. Development of central nervous system pathology in a murine transgenic model of human amyotrophic lateral sclerosis. Am. J. Pathol. 1994, 145, 1271-1279.

10. Onesto, E.; Colombrita, C.; Gumina, V.; Borghi, M.O.; Dusi, S.; Doretti, A.; Fagiolari, G.; Invernizzi, F.; Moggio, M.; Tiranti, V.; et al. Gene-specific mitochondria dysfunctions in human TARDBP and C9ORF72 fibroblasts. Acta Neuropathol. Commun. 2016, 4, 47. [CrossRef]

11. Wiedemann, F.R.; Winkley, K.; Kuznetsov, A.V.; Bartels, C.; Vielhaber, S.; Feistner, H.; Kunz, W.S. Impairment of mitochondrial function in skeletal muscle of patients with amyotrophic lateral sclerosis. J. Neurol. Sci. 1998, 156, 65-72. [CrossRef]

12. Allen, S.P.; Duffy, L.M.; Shaw, P.J.; Grierson, A.J. Altered age-related changes in bioenergetic properties and mitochondrial morphology in fibroblasts from sporadic amyotrophic lateral sclerosis patients. Neurobiol. Aging 2015, 36, 2893-2903. [CrossRef]

13. Konrad, C.; Kawamata, H.; Bredvik, K.; Arreguin, A.; Cajamarca, S.A.; Hupf, J.C.; Ravits, J.; Miller, T.M.; Maragakis, N.J.; Hales, C.M.; et al. Fibroblast bioenergetics to classify amyotrophic lateral sclerosis patients. Mol. Neurodegener. 2017, 12, 76. [CrossRef] 
14. Codron, P.; Cassereau, J.; Vourc'H, P.; Veyrat-Durebex, C.; Blasco, H.; Kane, S.; Procaccio, V.; Letournel, F.; Verny, C.; Lenaers, G.; et al. Primary fibroblasts derived from sporadic amyotrophic lateral sclerosis patients do not show ALS cytological lesions. Amyotroph. Lateral Scler. Front. Degener. 2018, 19, 446-456. [CrossRef]

15. Smith, E.F.; Shaw, P.J.; De Vos, K.J. The role of mitochondria in amyotrophic lateral sclerosis. Neurosci. Lett. 2019, 710, 132933. [CrossRef]

16. Villena, J.A. New insights into PGC-1 coactivators: Redefining their role in the regulation of mitochondrial function and beyond. FEBS J. 2015, 282, 647-672. [CrossRef]

17. Thau, N.; Knippenberg, S.; Korner, S.; Rath, K.J.; Dengler, R.; Petri, S. Decreased mRNA expression of PGC- $1 \alpha$ and PGC- $1 \alpha$ regulated factors in the SOD1G93A ALS mouse model and in human sporadic ALS. J. Neuropathol. Exp. Neurol. 2012, 71, 1064-1074. [CrossRef]

18. Russell, A.; Wada, S.; Vergani, L.; Hock, M.B.; Lamon, S.; Léger, B.; Ushida, T.; Cartoni, R.; Wadley, G.D.; Hespel, P.; et al. Disruption of skeletal muscle mitochondrial network genes and miRNAs in amyotrophic lateral sclerosis. Neurobiol. Dis. 2013, 49, 107-117. [CrossRef]

19. Liang, H.; Ward, W.F.; Jang, Y.C.; Bhattacharya, A.; Bokov, A.F.; Jernigan, A.; Richardson, A.; Van Remmen, H. PGC- $1 \alpha$ protects neurons and alters disease progression in an amyotrophic lateral sclerosis mouse model. Muscle Nerve 2011, 44, 947-956. [CrossRef]

20. Zhao, W.; Varghese, M.; Yemul, S.; Pan, Y.; Cheng, A.; Marano, P.; Hassan, S.; Vempati, P.; Chen, F.; Qian, X.; et al. Peroxisome proliferator activator receptor gamma coactivator-1alpha (PGC-1 $\alpha$ ) improves motor performance and survival in a mouse model of amyotrophic lateral sclerosis. Mol. Neurodegener. 2011, 6, 51. [CrossRef]

21. Nijland, P.G.; Witte, M.E.; van het Hof, B.; van der Pol, S.; Bauer, J.; Lassmann, H.; van der Valk, P.; de Vries, H.E.; van Horssen, J. Astroglial PGC-1alpha increases mitochondrial antioxidant capacity and suppresses inflammation: Implications for multiple sclerosis. Acta Neuropathol. Commun. 2014, 2, 170. [CrossRef]

22. Da Cruz, S.; Parone, P.A.; Lopes, V.S.; Lillo, C.; McAlonis-Downes, M.; Lee, S.K.; Vetto, A.P.; Petrosyan, S.; Marsala, M.; Murphy, A.N.; et al. Elevated PGC-1 $\alpha$ Activity Sustains Mitochondrial Biogenesis and Muscle Function without Extending Survival in a Mouse Model of Inherited ALS. Cell Metab. 2012, 15, 778-786. [CrossRef]

23. Gurney, M.; Pu, H.; Chiu, A.; Canto, M.D.; Polchow, C.; Alexander, D.; Caliendo, J.; Hentati, A.; Kwon, Y.; Deng, H.-X.; et al. Motor neuron degeneration in mice that express a human $\mathrm{Cu}, \mathrm{Zn}$ superoxide dismutase mutation. Science 1994, 264, 1772-1775. [CrossRef]

24. Muller, F.L.; Liu, J.; Jernigan, A.; Borchelt, D.; Richardson, A.; Van Remmen, H. MnSOD deficiency has a differential effect on disease progression in two different ALS mutant mouse models. Muscle Nerve 2008, 38, 1173-1183. [CrossRef]

25. Boillée, S.; Yamanaka, K.; Lobsiger, C.S.; Copeland, N.G.; Jenkins, N.A.; Kassiotis, G.; Cleveland, D.W. Onset and progression in inherited ALS determined by motor neurons and microglia. Science 2006, 312, 1389-1392. [CrossRef]

26. Fernandez-Marcos, P.J.; Auwerx, J. Regulation of PGC-1 $\alpha$, a nodal regulator of mitochondrial biogenesis. Am. J. Clin. Nutr. 2011, 93, 884S-890S. [CrossRef]

27. Liu, Y.; Okada, T.; Nomoto, T.; Ke, X.; Kume, A.; Ozawa, K.; Xiao, S. Promoter effects of adeno-associated viral vector for transgene expression in the cochlea in vivo. Exp. Mol. Med. 2007, 39, 170-175. [CrossRef]

28. Klein, R.L.; Hamby, M.E.; Gong, Y.; Hirko, A.C.; Wang, S.; Hughes, J.A.; King, M.A.; Meyer, E.M. Dose and promoter effects of adeno-associated viral vector for green fluorescent protein expression in the rat brain. Exp. Neurol. 2002, 176, 66-74. [CrossRef]

29. Eschbach, J.; Schwalenstöcker, B.; Soyal, S.M.; Bayer, H.; Wiesner, D.; Akimoto, C.; Nilsson, A.-C.; Birve, A.; Meyer, T.; Dupuis, L.; et al. PGC-1 is a male-specific disease modifier of human and experimental amyotrophic lateral sclerosis. Hum. Mol. Genet. 2013, 22, 3477-3484. [CrossRef]

30. Herrera-Marcos, L.V.; Sancho-Knapik, S.; Gabás-Rivera, C.; Barranquero, C.; Gascón, S.; Romanos, E.; Martínez-Beamonte, R.; Navarro, M.A.; Surra, J.C.; Arnal, C.; et al. Pgcla is responsible for the sex differences in hepatic Cidec/Fsp27ß mRNA expression in hepatic steatosis of mice fed a Western diet. Am. J. Physiol. Metab. 2020, 318, E249-E261. [CrossRef] 
31. Capllonch-Amer, G.; Sbert-Roig, M.; Galmes-Pascual, B.M.; Proenza, A.M.; Llado, I.; Gianotti, M.; Garcia-Palmer, F.J. Estradiol stimulates mitochondrial biogenesis and adiponectin expression in skeletal muscle. J. Endocrinol. 2014, 221, 391-403. [CrossRef]

32. Xiang, Z.; Valenza, M.; Cui, L.; Leoni, V.; Jeong, H.-K.; Brilli, E.; Zhang, J.; Peng, Q.; Duan, W.; Reeves, S.A.; et al. Peroxisome-proliferator-activated receptor gamma coactivator $1 \alpha$ contributes to dysmyelination in experimental models of Huntington's disease. J. Neurosci. 2011, 31, 9544-9553. [CrossRef]

33. Kiaei, M.; Kipiani, K.; Chen, J.; Calingasan, N.Y.; Beal, M.F. Peroxisome proliferator-activated receptor-gamma agonist extends survival in transgenic mouse model of amyotrophic lateral sclerosis. Exp. Neurol. 2005, 191, 331-336. [CrossRef]

34. Schütz, B.; Reimann, J.; Dumitrescu-Ozimek, L.; Kappes-Horn, K.; Landreth, G.E.; Schurmann, B.; Zimmer, A.; Heneka, M.T. The oral antidiabetic pioglitazone protects from neurodegeneration and amyotrophic lateral sclerosis-like symptoms in superoxide dismutase-G93A transgenic mice. J. Neurosci. 2005, 25, 7805-7812. [CrossRef]

35. Shibata, N.; Kawaguchi-Niida, M.; Yamamoto, T.; Toi, S.; Hirano, A.; Kobayashi, M. Effects of the PPAR $\gamma$ activator pioglitazone on $\mathrm{p} 38 \mathrm{MAP}$ kinase and $\mathrm{I} \kappa \mathrm{B} \alpha$ in the spinal cord of a transgenic mouse model of amyotrophic lateral sclerosis. Neuropathology 2008, 28, 387-398. [CrossRef]

36. Dupuis, L.; Dengler, R.; Heneka, M.T.; Meyer, T.; Zierz, S.; Kassubek, J.; Fischer, W.; Steiner, F.; Lindauer, E.; Otto, M.; et al. A randomized, double blind, placebo-controlled trial of pioglitazone in combination with riluzole in amyotrophic lateral sclerosis. PLoS ONE 2012, 7, e37885. [CrossRef]

(C) 2020 by the authors. Licensee MDPI, Basel, Switzerland. This article is an open access article distributed under the terms and conditions of the Creative Commons Attribution (CC BY) license (http://creativecommons.org/licenses/by/4.0/). 